\title{
CIRSIUM OLERACEUM L. SCOP. INHIBITS CELL VIABILITY AND DECREASES SECRETION OF MATRIX METALLOPROTEINASES (MMP2 AND MMP9) IN GLIOBLASTOMA CELL LINE
}

\author{
SYLWIA K. NALIWAJKO', RENATA MARKIEWICZ-ŻUKOWSKA'', JUSTYNA MOSKWA', \\ IRENA KASACKA², KRYSTYNA GROMKOWSKA-KĘPKA', PATRYK NOWAKOWSKI', \\ KATARZYNA SOCHA ${ }^{1}$ and MARIA H. BORAWSKA ${ }^{1 *}$
}

${ }^{1}$ Department of Bromatology, Medical University of Białystok, Poland ${ }^{2}$ Department of Histology and Cytophysiology, Medical University of Białystok, Poland

\begin{abstract}
The aim of this study was to evaluate the activity of Cirsium oleraceum L. Scop. methanol extract (CoM) on likely glioblastoma (U87MG) and normal human astroglia (SVGp12) cell lines. CoM in concentrations $25 ; 50 ; 100 ; 250$ and $500 \mu \mathrm{g} / \mathrm{mL}$ inducting significant dose- and time-dependent reductions of U87MG, as well as SVGp12 cells viability, in particular after $72 \mathrm{~h}$ of incubation. Activation of caspase-3 in U87MG cells suggests the pro-apoptotic activity of CoM. Moreover, CoM decreased secretion of matrix metalloproteinases (MMP2 and MMP9) and moderately decreased migration of U87MG cells in scratch test. These results suggest that Cirsium oleraceum L. Scop. methanol extract has anti-glioma effect in vitro through activation of caspase3 and inhibition of metalloproteinase-2 and -9 in U87MG cells. Despite this, cytotoxic effect of CoM in normal human astroglia cells may limit its potential application in the adjuvant therapy of glioblastoma.
\end{abstract}

Keywords: Cirsium oleraceum, glioblastoma, metalloproteinases

Currently, many efforts are underway to develop new therapeutic anti-cancer drugs from natural sources. A major natural reservoir is plant material (1). Cirsium Mill., a member of the family Asteraceae, is a perennial herb found in many areas of the world. Plants of the genus Cirsium Mill. have been used in medicine for ages (2). One of the species is C. oleraceum, which has been used in traditional medicine as an anti-hemorrhagic, antihypertensive, anti-hepatitis and uretic (3). Several studies have shown that the chemical composition of Cirsium Mill. is characterized by the presence of many constituents such as flavonoids, phenolic acids, sterols, volatile oils and long-chain alcohols $(4,5)$. The activity of Cirsium Mill. species mainly depends on the presence of phenolic compounds.

Several studies confirm antioxidant (6), antidiabetic (7), anti-inflammatory (8), antihemorrhagic (9), antimicrobial $(10,11)$, as well as neuroprotective (12) and hepatoprotective (13) activities of plants from Cirsium Mill. genus. In a few studies, extracts from Cirsium Mill. and its compounds were reported to have anticancer properties. However, the influ- ence of $C$. oleraceum on glioblastoma multiforme (GBM) has not been analyzed.

GBM is the most aggressive from all the gliomas. According to the World Health Organization (WHO) gliomas are divided into four grades, the most invasive is grade 4 - GBM. Despite standard treatments consisting of surgery, postoperative radiotherapy, and chemotherapy with temozolomide. Patient survival remains poor, which is mainly attributed to tumor inherent radio- and chemoresistance $(14,15)$.

The aim of this study was to evaluate the influence of $C$. oleraceum extract on glioblastoma (U87MG) and human astroglia (SVGp12) cell lines.

\section{EXPERIMENTAL}

\section{Chemicals}

Acrylamide/bis-acrylamide solution, ammonium persulfate, bovine serum albumin, calcium chloride, Coomassie brilliant blue (CBB), dimethyl sulfoxide (DMSO), gelatin, glycine, methanol, SDS, TEMED, Thiazolyl Blue Tetrazolium Bromide

\footnotetext{
* Corresponding author: e-mail: bromatos@umb.edu.pl
} 
(MTT), Triton X-100 and Tris were purchased from Sigma-Aldrich (St. Louis, MO, USA). Minimal Essential Medium Eagle (MEM) and fetal bovine serum (FBS) were purchased from Gibco Life Technologies (Paisley, UK); phosphate buffered saline (PBS), penicillin-streptomycin and trypsinEDTA from PAA Laboratories (Pasching, Austria). Protein standard was purchased from Bio-Rad (Hercules, CA, USA). Normal rabbit serum (Vector Laboratories, Burlingame, USA). Peroxidase Blocking Reagent S 2001, Secondary antibody from Kit EnVision (+) K 4011, Target Retrieval Solution S 1699, Wash Buffer S 3006 were purchased from Dako (Glostrup, Denmark). Caspase-3 Rabbit antiHuman Polyclonal Antibody (LifeSpan Biosciences, Seattle, USA). QS hematoxylin (Vector Laboratories; Burlingame, USA).

\section{Plant material and preparation of extract}

Cirsium oleraceum L. Scop. was collected from the area of north-eastern Poland in 2013. Voucher specimens were deposited in the Department of Bromatology in the Medical University of Bialystok. Dried herb material was crushed and extracted two times on a shaker with a mixture of methanol: water: trifluoroacetic acid (50 : 50 : 0.1) (C. oleraceum methanol extract - CoM). The extract was filtered, concentrated under vacuum and lyophilized. CoM was protected from light and kept frozen at $-20^{\circ} \mathrm{C}$. The yield of the prepared extract $(\% \mathrm{w} / \mathrm{w})$ in terms of the starting material was 21.5. The extract was dissolved in DMSO and prepared as $1000 \mu \mathrm{g} / \mathrm{mL}$ stock solution in cell culture medium.

a

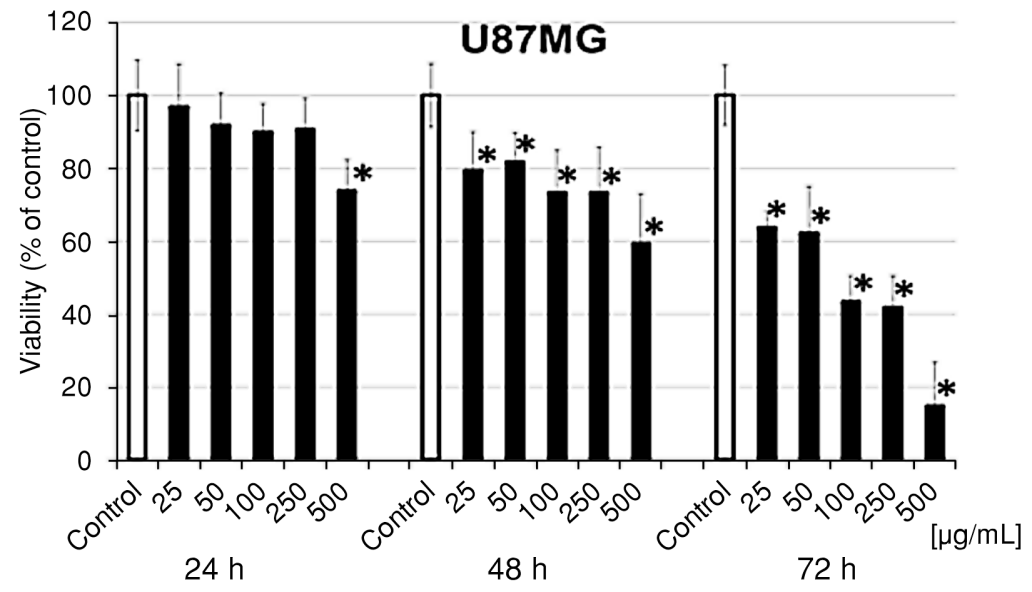

b

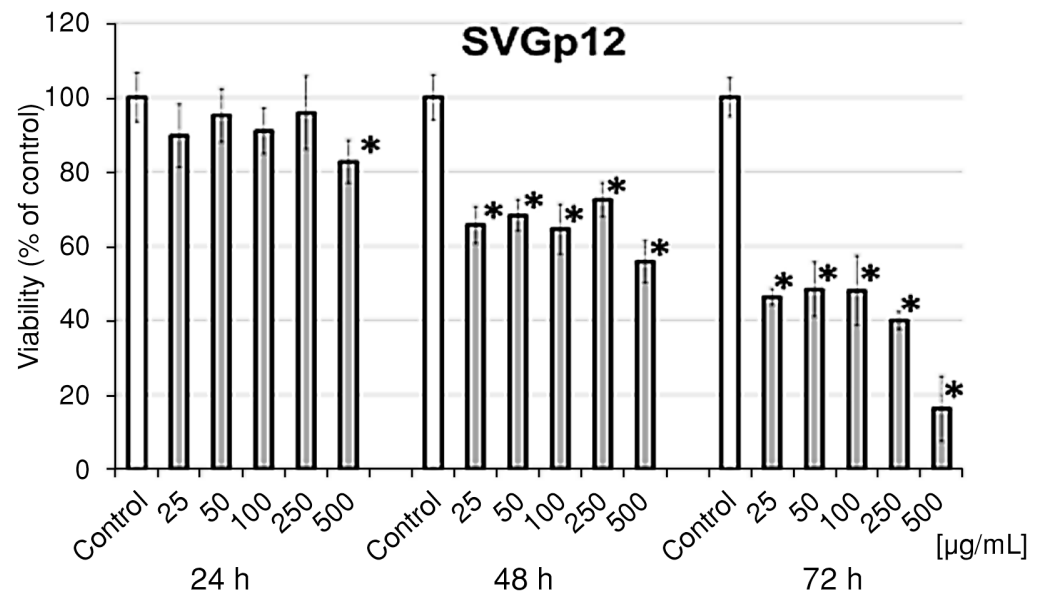

Figure 1. The viability of U87MG (a) and SVGp12 (b) (\% of control) after incubation with C. oleraceum methanol extract 


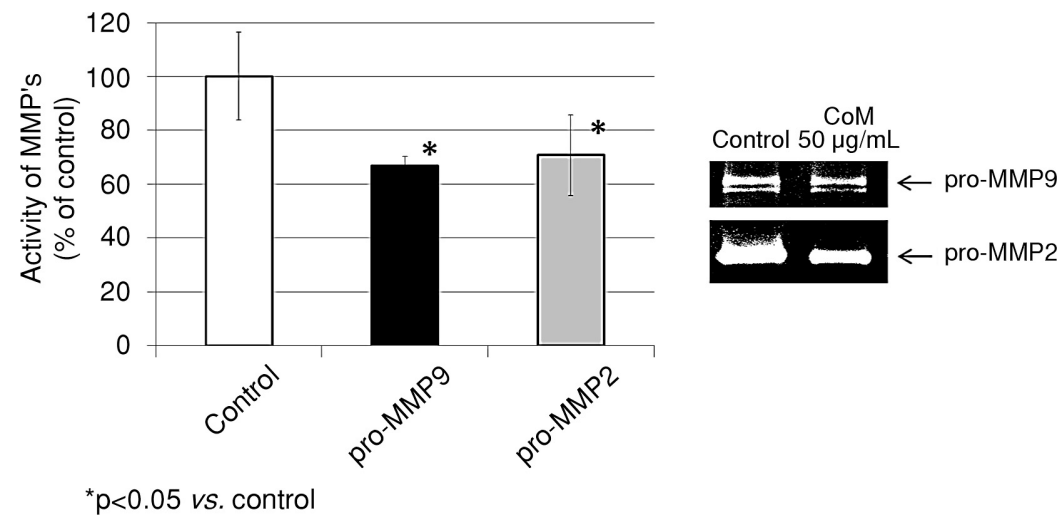

Figure 2. Inhibition of MMP`s secretion after $24 \mathrm{~h}$ incubation with C. oleraceum methanol extract ( $50 \mu \mathrm{g} / \mathrm{mL})$ in U87MG cells (\% of control). The picture is a representative gels of three independent experiments (medium concentrated by 35-fold; pro-MMP9 - $1 \mu \mathrm{g}$ of protein; MMP2 $-7 \mu \mathrm{g}$ of protein). ${ }^{*} \mathrm{p}<0.05-$ significant changes vs. control

\section{Cell viability assay}

Human likely glioblastoma cell line (U87MG) and normal human astroglial cell line (SVGp12) were obtained from American Type Culture Collection (ATCC, Rockville, MD, USA). The cell viability was measured using MTT assay as previously described for U87MG and SVGp12 (16). CoM was used in concentration of $25,50,100,250$, $500 \mu \mathrm{g} / \mathrm{mL}$. Cell viability was investigated after 24 , 48 and $72 \mathrm{~h}$. The data was expressed as a percentage of control (0.1\% DMSO). U87MG cells were used from passages 10-14 and SVGp12 - passages 7-9. Each experiment was performed in triplicate and repeated at last three times.

\section{Gelatin zymography}

The gelatin zymography was used for examination of activity of metalloproteinases (MMPs): MMP2 and pro-MMP9, as described previously (17). The cells were treated for $24 \mathrm{~h}$ with CoM in concentration $50 \mu \mathrm{g} / \mathrm{mL}$.

Immunohistochemistry (IHC) analysis of caspase-3

The U87MG cells were incubated with CoM $(50 \mu \mathrm{g} / \mathrm{mL})$ for $48 \mathrm{~h}$. The cells smears were prepared on adhesion slides (Ultra Plus Gold Menzel-Glasser) and fixed in $96 \%$ pure ethanol. IHC detection of apoptosis-related proteins was carried out. For antigen retrieval, the cells were subjected to pretreatment in a pressure chamber heating for $1 \mathrm{~min}$ at $21 \mathrm{psi}$ at $125^{\circ} \mathrm{C}$ using Target Retrieval Solution S 1699. After being cooled to room temperature, smears were incubated with Peroxidase Blocking Reagent S 2001 for 10 min to block endogenous peroxidase activity. The smears were incubated overnight at $4^{\circ} \mathrm{C}$ in a humidified chamber with the diluted Caspase- 3 Rabbit antiHuman Polyclonal Antibody (1 : 1,000), followed by incubation with secondary antibody (conjugated to horseradish peroxidase-labeled polymer). Bound antibodies were visualized by 1-min incubation with liquid 3,3'-diaminobenzidine substrate chromogen $(\mathrm{DAB}+)$. The smears were finally counterstained in QS hematoxylin mounted and evaluated under a light microscope. Appropriate washing with Wash Buffer S 3006 was performed between each step. The specificity tests performed for the caspase- 3 antibody included: negative control where the antibodies were replaced by normal rabbit serum at the respective dilution and positive control which was done for specific tissue recommended by the producer; for caspase- 3 is the human the spleen. The cytological preparations were subjected to analysis, using a microscope.

\section{Migration test (scratch assay)}

In 24-well plates U87MG cells were cultured at $37^{\circ} \mathrm{C}$ in a humidified atmosphere of $5 \% \mathrm{CO} 2$ until more than $70 \%$ of confluent growth. The bottom surfaces of each well were scratched with a $20-300 \mu \mathrm{L}$ micropipette tip to the same length and width. U87MG cells were treated with CoM (50, 100, 250 $\mu \mathrm{g} / \mathrm{mL})$ and control ( $0.1 \%$ DMSO) and then incubated for $48 \mathrm{~h}$. The images of each treatment group were captured at $100 \times$ magnification, using an Olympus CKX 41 microscope and KcJunior programme.

\section{Statistical analysis}

All data were analyzed using Statistica software version 12.0 (StatSoft, Poland). The values were tested for normal distribution using the 
Shapiro-Wilk and Kolmogorov-Smirnov tests. Differences between two groups were analyzed by the Student t-test or the Mann-Whitney U test. The level of significance was taken as $\mathrm{p}<0.05$.

\section{RESULTS}

The viability of U87MG and SVGp12 after treatment with CoM

The percentage of cell viability was calculated relative to the control. CoM in concentrations 25; 50; $100 ; 250$ and $500 \mu \mathrm{g} / \mathrm{mL}$ inducting significant dose- and time-dependent reductions of U87MG, as well as SVGp12 cells viability (in comparison to the control) ranging from $14.6-63.8 \%$ and $16.2-48.3 \%$, respectively, after $72 \mathrm{~h}$ of incubation (Fig. 1).

\section{The production of MMPs in U87MG treated with CoM}

There were observed the significant inhibitory effect of CoM $(50 \mu \mathrm{g} / \mathrm{mL})$ on the secretion of proMMP9 (66.9 $\pm 15.0 \%$ vs control) and pro-MMP2 (70.8 $\pm 12.4 \%$ vs control) in U87MG cell line (Fig. 2).

\section{The activation of caspase-3 after treatment with CoM}

Immunohistochemistry for caspase-3 showed weak or none cytoplasmic staining in control cells
(Fig. 3 A, B). After treatment with CoM $50 \mu \mathrm{g} / \mathrm{mL}$ was observed moderate (Fig. 3 C, D) caspase-3 immunoreactivity.

\section{Cell migration after treatment with CoM}

As shown in Figure $4 \mathrm{CoM}$ in concentration $250 \mu \mathrm{g} / \mathrm{mL}$ moderate decreased the migration (more open spaces were observed) of U87MG cells after $48 \mathrm{~h}$ of incubation compared to the control. CoM in concentration $50 \mu \mathrm{g} / \mathrm{mL}$ did not have any effect on decreasing cell migration.

\section{DISCUSSION AND CONCLUSION}

In the present study, CoM inhibits both, U87MG and SVGp12 cells viability. Significant inhibition of viability of U87MG cells after 24 hours incubation (the highest dose $500 \mu \mathrm{g} / \mathrm{mL}$ ) and after 48, 72 hours in all using doses was observed (Fig. 1). Moderate reduction of cell migration was observed after $48 \mathrm{~h}$ of incubation in scratch test (Fig. 4). Extracts from Cirsium spp. and its compounds possess various biological activities, including antitumor activity. Amighofran et al. (18) indicated, that C. bracteosum extract shows activity against K562 leukemia cells with IC50 $19.9 \mu \mathrm{g} / \mathrm{mL}$ and Jurkat cells with IC50 $93.3 \mu \mathrm{g} / \mathrm{mL}$. However, the authors did not observe any remarkable effects on the cell cycle profile in flow cytometry analysis and no lad-

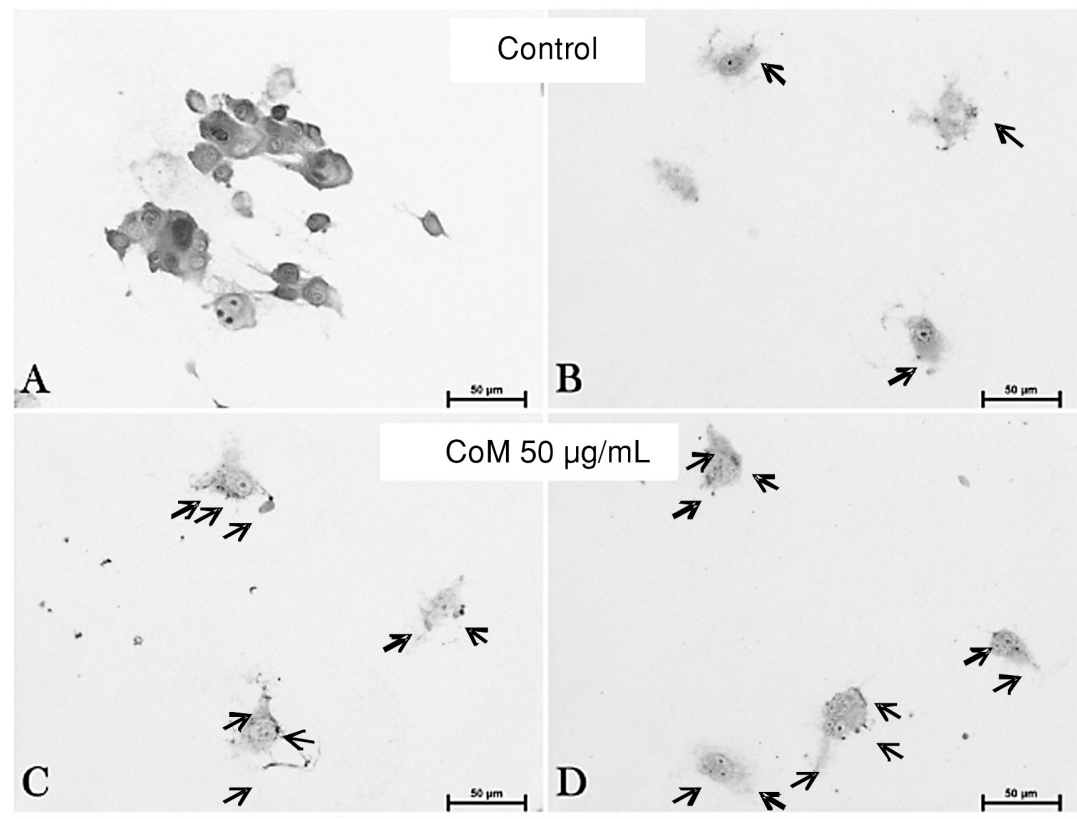

Figure 3. Representative micrographs of immunohistochemical staining of active caspase-3 (black arrows) in U87MG cells. A,B - control: A - no immunoreactivity, B - weak cytoplasmic staining; C,D - CoM $50 \mu \mathrm{g} / \mathrm{mL}-$ moderate immunoreactivity. Bar $=50 \mu \mathrm{m}$ 


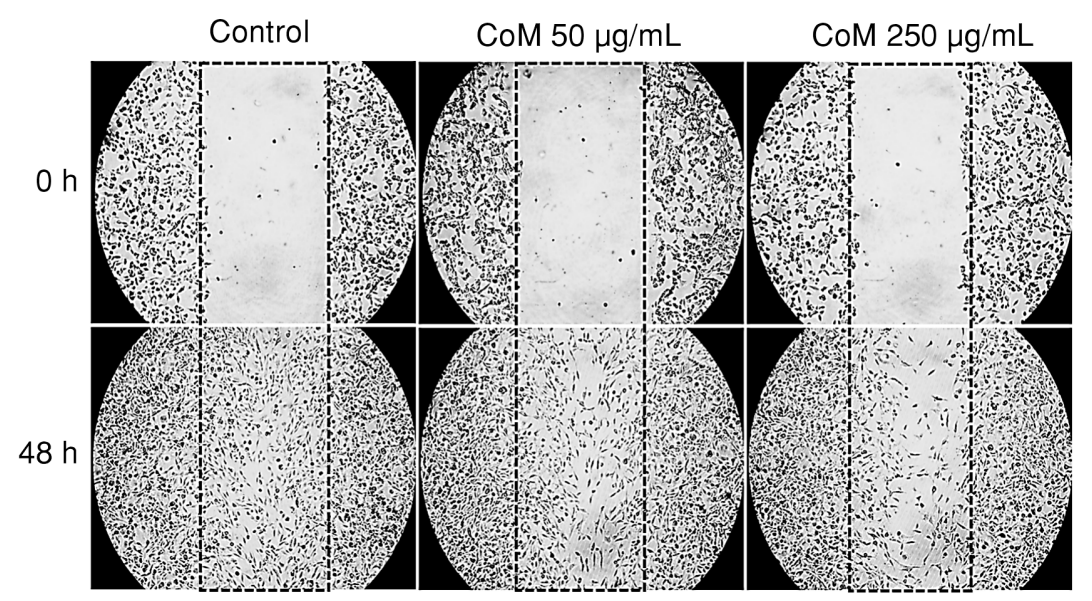

Figure 4. U87MG cells migration after $48 \mathrm{~h}$ of incubation with $C$. oleraceum methanol extract - CoM $(50 ; 250 \mu \mathrm{g} / \mathrm{mL})$

der formation in DNA fragmentation analysis of K562 and Jurkat cells. In Hungarian study, it was reported that $C$. vulgare extract in concentration of $10 \mu \mathrm{g} / \mathrm{mL}$ showed antiproliferative activity on cervical carcinoma (HeLa), but not on the breast cancer (MCF-7) or skin squamous carcinoma (A431) cell lines (19). In the study performed by Kim et al. was reported, that $C$. japonicum methanol extract induces the inhibition of MCF-7 cell growth at the proliferation (G1 phase cell cycle arrest) and apoptosis (affecting mitochondrial apoptotic events) levels (20). Other data, using an animal model, demonstrated that $C$. japonicum and its flavone components (pectolinarin and 5,7-dihydroxy-6,4'-dimethoxyflavone) induce the inhibition of tumor formation in the S180 and H22 mice and greatly inhibit cancer cell growth $(21,22)$.

Anticancer activity of Cirsium Mill. extract can be connected with chemical composition, in particular with the content of phenolic acids and flavonoids. The study about chemical composition of C. oleraceum from north-eastern Poland showed the presence of phenolic acids like protocatechuic and chlorogenic as well as $p$-hydroxybenzoic, caffeic, pcoumaric and ferulic $(10,23)$. In inflorescences, there were found also flavonoids: luteolin and apigenin (23). Protocatechuic acid shows widely biological activities, anti-inflammatory, antioxidant, anti-hyperglycemic, antibacterial and neurological properties. It has anticancer activity in particularly through inhibitory effects on VEGF-induced angiogenesis $(24,25)$. The data confirming anticancer potential of chlorogenic acid are promising. It was investigated, that chlorogenic acid markedly suppressed chemical-induced carcinogenesis and car- cinogenic metabolites through the activation of Nrf2/ARE pathway $(26,27)$. Apigenin has been shown to slow cancer growth and shrink cancerous tumors in animal studies (28).

CoM demonstrated the inhibitory effect on the viability of normal human astroglial cells. Generally, that is a negative effect. In pathological conditions, brain injury resulted in the formation of a glial scar resulting from reactive gliosis (mainly consisting of proliferated astrocytes) (29). The glial scar may be a physical and biochemical barrier for the regeneration of axons, which is why the researchers are looking for agents which inhibit astrocyte proliferation and glial scar formation in the late phase of the injury (30). It requires further study if CoM can be considered as a natural product modulating glial scar formation.

MMPs are endopeptidases collectively capable of degrading components of the extracellular matrix (EMC). MMPs play a role in physiological EMC remodeling, but in pathological conditions, they excessively damage of EMC. Expression of MMPs, especially MMP2 and MMP9 is upregulated in gliomas (31). These endopeptidases influence motility and proliferation of GBM and increase tumor cell invasion (32). After $24 \mathrm{~h}$ of incubation CoM inhibited estimated MMPs expression from cultured U87MG (Fig. 2). Nazaruk and Galicka showed the influence of compounds isolated from other species of Cirsium $-C$. palustre on the decrease of MMP2 from normal human skin fibroblasts (33).

In this study activation of caspase- 3 was observed after treatment with $\mathrm{CoM}$ (Fig. 3). It suggests the moderate pro-apoptotic activity of CoM in U87MG cells. 
These results suggest that $C$. oleraceum methanol extract have anti-glioma properties but also have cytotoxic effect in normal human astroglial cells. The anticancer effect may be associated with activation of caspase- 3 and inhibition of metalloproteinase- 2 and -9 in U87MG cells.

\section{Acknowledgments}

The presented work was financially supported by the Medical University of Bialystok, Poland (grant N/ST/ZB/16/008/2216).

\section{Conflict of interests}

The authors have declared that no conflict of interests exist.

\section{REFERENCES}

1. Khan M., Zheng B., Fei Y., Rasul A., Gu Z. et al.: Evid. Base Compl. Alternative Med. 2012:957568 (2012).

2. Nazaruk J., Brzóska T.: Post. Fitoter. 3, 170 (2008).

3. Viegi L., Pieroni A., Guarrera P.M., Vangelisti R.: J. Ethnopharmacol. 89, 221 (2003).

4. Kozyra M., Mardarowicz M., Kochmańska J.: Nat. Prod. Res. 29, 1942 (2015).

5. Bohm A.B., Stuess T.F.: Flavonoids of the Sunflower Family (Asteraceae), SpringerVerlag, Wien, New York 2001.

6. Deliorman Orhan D., Ergun F., Yesilada E., Tsuchiya K., Takaishi Y. et al.: Turk. J. Pharm. Sci. 4, 1 (2007).

7. Lai W.C., Wu Y.C., Dankó B., Cheng Y.B., Hsieh T.J., et al.: J. Nat. Prod. 25, 1624 (2014).

8. Lim H., Son K.H., Chang H.W., Bae K., Kang S.S., et al.: Biol. Pharm. Bull. 31, 2063 (2008).

9. Ishida H., Umino T., Tsuji K., Kosuge T.: Biol. Pharm. Bull. 35, 861 (1987).

10. Borawska M.H., Czechowska S.K., Markiewicz R., Socha K., Nazaruk J. et al.: Nat. Prod. Res. 24, 554 (2010).

11. Nazaruk J., Czechowska S.K., Markiewicz R., Borawska M.H.: Nat. Prod. Res. 22, 1583 (2008).

12. Yeo H.S., Kim D.W., Jun C.Y., Choi Y.K., Park C-H.: Korean J. Intern. Med. 28, 166 (2007).
13. Yoo Y.M., Nam J.H., Kim M.Y., Choi J., Park H.J.: Biol. Pharm. Bull. 31, 760 (2008).

14. Chaskis E., Luce S., Goldman S., Sadeghi N., Melot C. et al.: Bull. Cancer 18, 30172 (2018).

15. Scrideli C.A., Carlotti C.G. Jr, Okamoto O.K., Andrade V.S., Cortez M.A. et al.: J. NeuroOncol. 88, 281 (2008).

16. Borawska M.H., Markiewicz-Żukowska R., Naliwajko S.K., Moskwa J., Bartosiuk E. et al.: Nutr. Cancer 66, 1247 (2014).

17. Moskwa J., Borawska M.H., MarkiewiczZukowska R., Puscion-Jakubik A., Naliwajko S.K. et al.: PLoS One 9, 90533 (2014).

18. Amirghofran Z., Bahmani M., Azadmehr A., Javidnia K.: Neoplasma 53, 428 (2006).

19. Csupor-Löffler B., Hajdú Z., Réthy B., Zupkó I., Máthé I. et al.: Phytother. Res. 23, 1109 (2009).

20. Kim D.Y., Kang S.H., Ghil S.H.: Mol. Med. Rep. 3, 427 (2010).

21. Liu S., Luo X., Li D., Zhang J., Qiu D. et al.: Int. Immunopharmacol. 6, 1387 (2006).

22. Liu S., Zhang J., Li D., Liu W., Luo X. et al.: Nat. Prod. Res. 21, 915 (2007).

23. Nazaruk J., Szoka L: Herba Pol. 55, 32 (2009).

24. Hu J., Lin S., Huang J.J., Cheung P.C.K.: J. Agric. Food Chem. 66, 6742 (2018).

25. Khan A.K., Rashid R., Fatima N., Mahmood S., Mir S. et al.: Acta Pol. Pharm. 72, 643 (2015).

26. Shimizu M., Yoshimi N., Yamada Y., Matsunaga K., Kawabata K. et al.: J. Toxicol. Sci. 24, 433 (1999).

27. Boettler U., Volz N., Pahlke G., Teller N., Kotyczka C. et al.: Mol. Nutr. Food Res. 55, 798 (2011).

28. Mafuvadze B., Liang Y., Besch-Williford C., Zhang X., Hyder S.M.: Horm. Cancer. 3, 160 (2012).

29. Logan A., Berry M.: Adv. Exp. Med. Biol. 513, 115 (2002).

30. Zhang L., Zhang W.P., Chen K.D., Qian X.D., Fang S.H. et. al.: Life Sci. 80, 530 (2007).

31. Wang M., Wang T., Liu S., Yoshida D., Teramoto A.: Brain Tumor Pathol. 20, 65 (2003).

32. Zhao J.X., Yang L.P., Wang Y.F., Qin L.P., Liu D.Q. et al.: Eur. J. Neurol. 14, 510 (2007).

33. Nazaruk J., Galicka A.: Phytother. Res. 28, 1399 (2014).

Received: 11.07. 2018 